\title{
Quantifying the Consequences of Perceived Stress in the Textile and Clothing Sector through Structural Equation Modelling
}

\author{
Aftab Ahmad, ${ }^{1}$ Amjad Hussain, ${ }^{2}$ Asif Mahmood, ${ }^{3}$ Ayyaz Ahmad, ${ }^{4}$ Amir Ikram (D), \\ and Shagufta Yasmin 6 \\ ${ }^{1}$ Department of Electrical Engineering, NFC Institute of Engineering and Fertilizers Research (NFC-IEFR), Faisalabad, Pakistan \\ ${ }^{2}$ Department of Mechanical Engineering, University of Engineering and Technology, Lahore, Pakistan \\ ${ }^{3}$ Department of Business Studies, Namal Institute, Mianwali, Pakistan \\ ${ }^{4}$ Institute of Quality and Technology Management, University of the Punjab, Lahore, Pakistan \\ ${ }^{5}$ Institute of Business and Management, University of Engineering and Technology, Lahore, Pakistan \\ ${ }^{6}$ Department of Education, School of Social Sciences and Humanities, University of Management and Technology (UMT), \\ Lahore, Pakistan
}

Correspondence should be addressed to Amir Ikram; amirikram12@hotmail.com

Received 4 February 2021; Accepted 22 April 2021; Published 2 June 2021

Academic Editor: Kandasamy Jayakrishna

Copyright ( $2021 \mathrm{Aftab}$ Ahmad et al. This is an open access article distributed under the Creative Commons Attribution License, which permits unrestricted use, distribution, and reproduction in any medium, provided the original work is properly cited.

The textile and clothing $(\mathrm{T} \& \mathrm{C})$ sector plays an important role in the growth and industrial development of emerging economies. Work stress is a real concern for organizations with no immunity for the T\&C sector. It hampers individual as well as organizational work performance that ultimately places a significant hurdle in achieving competitiveness in the market. This study aims at exploring the antecedents and consequences of work stress and how different causes of stress influence perceived stress among the employees of the textile and clothing organizations in Pakistan. Data were collected from 1470 employees of 24 organizations. Cohen's Perceived Stress Scale-10 (PSS-10) and two researcher-developed instruments (34 items and 22 items each) were used for the data collection. Information gathered was analyzed by PLS-SEM (partial least squares structural equation modelling) technique. Statistically significant results were found for the antecedents, namely, work-family conflict, role clarity, work characteristics, social working environment, managers' support at work, and training and career development, with workfamily conflict as the most significant, and for the consequences, namely, psychological, emotional, physical, performance, and behavioral with psychological effect as the most significant. The findings of the study could help managers, designers, planners, and ergonomists in making more informed and proactive decisions while attempting to prevent or control the stress phenomenon in the T\&C sector. Moreover, the study highlights the need for gaining more in-depth insight into the work-stress phenomenon proactively so that the effectiveness of intervention strategies might be assured.

\section{Introduction}

The textile and clothing (T\&C) industry assumes a major role in the growth and industrial development of emerging economies and, hence, contributes to the global economy [1-3]. Also, as quoted by Cheng et al. [4], textile industry is acknowledged as a main economic area in developing countries. In some countries, textiles and clothing are the main export-oriented industrial sector, for example, Bangladesh has complete reliance on textiles and garments with an $83.5 \%$ share of the total manufacturing exports, followed by Sri Lanka with $47 \%$ and Pakistan with 67.2\% [5]. The T\&C sector in Pakistan is one of the most prominent manufacturing industries that assume a central part in the country's economy as it offers employment to $30 \%$ of the country's total workforce, adds $8.5 \%$ to GDP, and continues to be the lifeblood for the country's exports at $52 \%$ of the total trade $[6,7]$. Pakistan is amongst the main textiles producing regions of the world, as quoted by Wang et al. [8]. 
Work stress is a real concern for organizations with no immunity for the T\&C sector. It hampers individual as well as organizational work performance that ultimately places a significant hurdle in achieving competitiveness in the market. Besides requiring the optimal utilization of resources, there is a need to implement the international standards related to the health and safety environment of organizations, fundamental human rights, etc. Workplace stress management is amongst the human resource management practices that have been found to be strong stimulator maximizing organizational execution [9]. The International Labour Organization [10] has called for improvements in compliance with International Labour Standards in the textile sector of Pakistan. The financial impact of workplace stress on organizations is enormous. It is revealed that, about $18 \%$ of working men and $25 \%$ of working women suffer from workplace stress [11]. In a recent VicHealth commission study, "\$730 million over one year and $\$ 11.8$ billion over a lifetime" have been anticipated as the cost of depression ascribed to work stress in the Australian working population. Employment ascribed the bulk of these costs, e.g., absenteeism and job turnover [11]. Likewise, forty million employees in the European Union suffered from jobassociated stress [12]. According to a poll conducted by American Psychological Association [13], about 36\% of the employees remained stressed throughout the working week which ultimately affected the organizational performance negatively and resulted in negative financial impact.

Keeping in view the importance of stress management, considerable work has been done (for example, Arnold et al. [14] and Kitronza and Mairiaux [15]) to identify the causes and consequences of workplace stress in different sectors. However, the stress literature on the T\&C sector is scarce. Moreover, there is a need to further investigate the stress phenomenon and its complex underlying relationships with varying factors in T\&C sector of developing countries so that more realistic and pragmatic prevention strategies may be designed and implemented. Furthermore, while attempting to prevent or control the stress phenomenon, it is perhaps inadequate merely to know about the causes of work stress. So, this study not only aims at finding the causes and consequences of workplace stress but also investigates the relationships of different contributing and resulting factors with the perceived stress in T\&C sector organizations.

First, using exploratory sequential mixed methods' design, instruments for measuring antecedents and consequences of work stress were developed. Later, using these instruments and Cohen's PSS-10 scale, data were collected for the antecedents and consequences of work stress, as well as for the perceived stress. Finally, PLSSEM was applied to the information gathered to achieve the objectives of the study. The results obtained through these techniques can be used to understand the role of different factors causing stress at work, and how each of them impacts the employees' perceived stress level. Investigation of the causes in terms of their impact on perceived stress levels may help to reduce high impact causes, which, in turn, will result in promoting more effective and sustainable intervention mechanisms at work.

\section{Literature Review}

2.1. Perceived Stress. According to Selye, stress is "the nonspecific response of the body to any demand made on it" [16]. Later, he described it as "the state manifested by a specific syndrome which consists of all the nonspecifically induced changes within the biological system" [17]. According to Lumsden [18], stress is viewed as "hardship or adversity," while Cox and Griffiths [19] have described it as an "engineering approach." Lazarus [20] gave the concept of cognitive appraisal according to which stress is the result of inequality between the demands placed on the person and the person's resources to fulfill those demands $[20,21]$. Stress is also defined as a negatively perceived anomaly which, because of inadequate dealing with the stressors, has adverse mental and physical health-related impacts [22-24]. Researchers have also investigated the attributes of "person-environment interaction" and, more considerably, the psychological progression through which it occurs [25]. Consequently, the modern outlook led the researchers to consider stress as the outcome of a "transaction" between the environment and the individual. The term "transaction" means stress is neither in the individual nor in the environment but the interconnection between the two [26]. Stress is increased when the individual perceives the demand for a particular transaction more than the resources available [27]. Therefore, stress arises when the extent of the stressor goes beyond the individual's coping capacity. Nevertheless, perceived stress is an overall assessment of one's stress and is the extent to which people find their lives "uncontrollable, unpredictable, and overloading" [28].

2.2. Antecedents of Work Stress. Substantial work has been done in identifying the antecedents of workplace stress in different sectors. In a study of sports performers, targets and execution stressors (time and intensity) and team and environment stressors (frequency and intensity) were found as organizational stressors [14]. In other studies, it was ascertained that relationship conflict and nontask organizational conflict [29], workplace bullying [30], alcohol consumption [15], and execution of illegitimate tasks are the causes of the employees' job stress $[31,32]$. Likewise, in other studies, high work-related demands, poor interpersonal communication, role ambiguity, working environment, and career development [33] have been identified as the job stressors. Therefore, working conditions, as well as the health and safety situation, in the textile and clothing sector organizations of Pakistan were found unfavorable to higher productivity [34]. Multiple hazards such as inadequate physical working conditions along with unacceptable temperature, humidity, and noise levels highlighted the need for training, awareness, and top management commitment [34].

2.3. Consequences of Work Stress. It is noteworthy that the effects of stress are reckoned to a degree by how the individuals react to it. For example, people for certain distressful situations are strong enough that they handle these situations easily, while in other cases, their response to the distressing circumstances might be unpleasant to their prosperity. Work stress has a negative effect on the 
individual and organizational work performance $[35,36]$ and results in decreased efficiency, reduced capacity to work, diminished zeal, the rigidity of thoughts, absence of compassion for the organization and allies, increased turnover, lost commitment, and self-esteem [37-40]. It affects the human body negatively and results in nervousness, mental issues, stomach problems, and cardiovascular ailments [36], while prolonged severe stress has predicted poorer mental and physical health in young adulthood [41]. Similarly, loss of interest in the practice, tiredness, boredom, decline in health-related quality of life, and lack of focus and hindrance of alertness [42] were the effects of stress [43]. Likewise, a study on older African Americans revealed that higher levels of perceived stress cause quick declines in overall cognition [44]. Moreover, a study conducted on university employees concludes a higher level of depression and anxiety impact job satisfaction negatively [45]. An investigation conducted on the employees working in shifts identified that workplace stress affects employees' mental health negatively [46]. A study was carried among male and female workers to identify the effect of stress on their smoking behaviors in relation to gender differences. The study revealed a strong positive correlation between stress and increased smoking [47] where the effect was more for female workers. In a metaanalysis, quality of life was found to be negatively related to stress, and factors such as insomnia and burnout were also correlated with the deterioration [48].

\section{Methodology}

3.1. The Proposed Hypothetical Model. The conceptual and empirical research studies carried out in the areas of concern mentioned in Section 2 have yielded numbers of antecedents and consequences of work stress. On the basis of the theoretical background achieved from earlier studies and the current on ground scenario captured through the observations and interviews, some hypotheses were proposed to study this research and are placed in Table 1.

3.2. General. In attaining the research objectives, this study carried out a comprehensive literature review of journal papers, proceedings, and reports on the topic of job stress and its probable sources and consequences. Exploratory sequential mixed methods design has been used in the research project where qualitative and quantitative information was gathered. It is an approach that combines qualitative and quantitative data collection and analysis in a sequence of phases. There may be multiple causes and consequences of stress at work which may vary from sector to sector and also from region to region. The situation necessitated the development of the sector as well as region-specific instruments. Under this motivation, the instruments were developed. For getting an in-depth insight into the prevailing situation in the selected industrial sector and incorporating the necessary information for the survey instrument, physical observations and focus group discussions were carried out in some textile and clothing sector organizations. The process helped in designing the data collection instruments for the antecedents
TABLE 1: Hypotheses of the study.

H1.1: existence of the physical hazards at the workplace is positively correlated with the work stress

H1.2: absence of role clarity is positively correlated with the work stress

H1.3: absence of control and decision latitude among the employees is positively linked with the work stress

H1.4: dearth of career development and training of the employees is positively related to the workplace stress

H1.5: work-family conflict is positively related with work stress H1.6: poor working conditions at the workplace are positively correlated with the work stress

H1.7: poor hygienic conditions are positively correlated with the work stress

H1.8: poor work characteristics are positively correlated to the work stress

H1.9: lack of managers' support at work is positively correlated with employees work stress

H1.10: poor social working environment is positively correlated with the employee work stress

H2.1: the employee work stress and thereupon "negative physical effects" on them are significantly correlated

H2.2: employee work stress is negatively correlated with the employee's performance

H2.3: employee job stress affects employees' emotions negatively H2.4: employee work stress has negative effects on the employees' behaviors

$\mathrm{H} 2.5$ : the impact of work environment stress on the employees is hypothesized to be positive with the employees' psychology

and the consequences of stress in order to meet the objectives of the study. Deploying exploratory factor analysis (EFA) on the data collected through a pilot study, instruments were finalized for the final data collection. These instruments were named as Antecedents of Perceived Stress (APS) and Consequences of Perceived Stress (CPS). However, being not the purview of the study, the detailed procedure for the instrument development (part of phase 1) has not been illustrated here. Furthermore, Sheldon Cohen's PSS-10 (Perceived Stress Scale-10), an established instrument, was used to measure the perceived stress of the participants [49]. This scale is one of the well-accepted instruments for gauging psychological stress. It is a self-reported instrument developed to determine "the degree to which individuals appraise situations in their lives as stressful." A number of researchers have extensively used the said scale [50-53]. The research strategy used in the present study was a cross-sectional survey. Before running the survey, measures were handed out to the participants and all of them were informed about the inspiration driving the research and its procedure and substance.

3.3. Participants and Procedure. The study was carried out on the employees $(N=1470)$ of 24 export-based textile organizations in Pakistan. For collecting a more comprehensive and diverse opinion pool, four zones of the textile sector, explicitly, fibric manufacturing, home textiles, apparel manufacturing, and socks manufacturing were selected. Irrespective of gender, individuals were employed in divergent positions in diverse departments with varied career spans qualified for inclusion in the study. No minimum period of employment years was required 
for the participants to be included in the survey. Permission for conducting surveys was sought in writing from multiple textile and clothing sector organizations and thereupon telephonically as well as in-person follow-up was made. The survey was carried out after getting ethical approval from the employer of the respective organization. The chosen 24 companies are those which accorded permission. Therefore, the sampling used in the study, up to the extent of organization selection, is convenience sampling. These 24 companies represent the major subsectors of T\&C, namely, fiber/fabric manufacturer, apparel/garment manufacturer, socks manufacturer, and home textiles. Before completing the survey, the questionnaire was handed out to the participants and all of them were informed about the inspiration driving the research as well as its procedure and substance. The survey administers remained accessible to the respondents throughout the process of recording their responses so that they could help them in case of queries. They also checked the filled questionnaires immediately for any omitted information. The anonymity of information supplied by the individuals was guaranteed.

3.4. Instruments. Three survey instruments were deployed to attain the goals of the study.

3.4.1. Instrument for Perceived Stress (Cohen's PSS-10). PSS-10 is a well-established tool to measure the perceived stress [49]. As evident from the name, it consists of 10 items (Table 2). As shown in Appendix A in Supplementary materials (available here), in the PSS-10 scale, respondents were to react on a 5 -point scale which ranged from 0 (never) through 4 (always), where 0 designates no stress and 4 designates high stress: 0_never, 1_seldom, 2_ sometimes, 3 _ often, and 4_always. The items (worded positively) at serial numbers $4,5,7$, and 8 were reversed in their direction for score calculations. The internal consistency of this instrument was also confirmed through Cronbach's alpha value and was found as 0.741 (Table 3), a quite reasonable value [54].

3.4.2. Instrument for Antecedents (APS). APS is a selfdesigned instrument and consisted of 34 items. It was used to identify the antecedents of work stress. Here, the opinion of the participants was acquired on a 5-point Likert-type scale which ranged from 1 (signifying no stress) through 5 (signifying high stress): $5=$ strongly agree or always, $4=$ agree or often, 3 = partially agree or sometimes, $2=$ disagree or seldom, and $1=$ totally disagree or never, as per the need of the given statements. However, for positive items, the scores were reversed. The reliability of the instrument was confirmed through Cronbach's alpha values and found as 0.921 (Table 3), much above the minimum threshold of 0.70 [54].

3.4.3. Instrument for Consequences (CPS). CPS emerged from 22 items was also a self-designed instrument developed to identify the consequences of work stress. Again, the opinions of the respondents were recorded on a 5-point Likert-type scale which ranged from 1 (signifying no stress) through 5 (signifying high stress): $5=$ strongly agree or always, $4=$ agree or often, $3=$ partially agree or sometimes, 2 = disagree or seldom, $1=$ totally disagree or never (Appendix A in Supplementary Materials). The reliability of the instrument was confirmed through Cronbach's alpha values and found as 0.940 (Table 3), a reliable value [54].

3.5. Statistical Procedure. First of all, the study investigated potential stress components for both the antecedents and the consequences by using EFA where PCA (principal component analysis) was used as an extraction technique and Oblimin with Kaiser Normalization as the rotation. Contrary to common factor analysis, PCA is the default extraction method of factor analysis, and researchers have extensively used it in similar studies $[55,56]$. Finally, this study utilized the PLS-SEM to find the associations linking the components identified and the perceived stress. SPSS version 23 and Smart PLS 3.2.8 were employed to carry out the statistical analyses [57].

\section{Results}

4.1. Exploratory Factor Analysis. $\mathrm{KMO}$ values between 0.8 and 1 indicate the sampling is adequate [58]. The KMO values for antecedents as well as consequences, as shown in Table 4, clearly indicated the adequacy of data for factor analysis. Also, the significance value of Bartlett's test of sphericity as 0.0001 (less than the threshold of 0.001 [59]) showed the validity and suitability of the information collected for EFA.

The EFA yielded 10 components (34 items) for the antecedents and 5 components (20 items) for the consequences of stress. The instrument for consequences (CPS) was composed of " 22 " items; however, the deployment of the EFA on the data collected resulted in 5 components comprising " 20 " items. The components extracted for the antecedents as well as for the consequences described an adequate cumulative variance of $70.6 \%$ and $67.2 \%$, respectively, surpassing the threshold of $60 \%$. The extraction of the components was done based on the screen plot approach. In both cases, the loading of items on their respective components was beyond or around 0.50 . The components were named in accordance with their relevance to the items loaded on them, as shown in Table 5.

4.2. Partial Least Square Structural Equation Modelling (PLSSEM). This study employed Smart PLS 3 release 3.2.8 software [60] to investigate the relationships of perceived stress with the antecedents and the consequences. Interpretation of the results involves two steps: assessment of the measurement model and evaluation of the structural model.

4.2.1. Testing the Measurement Model. The results of the measurement model disclose that every single least prerequisite was fulfilled for further analysis (Figure 1, Tables 6 and 7, and Appendices A-C in Supplementary Materials). 
TABLE 2: Items of instrument for perceived stress (Cohen's PSS-10).

\begin{tabular}{|c|c|c|c|}
\hline Item no. & \multicolumn{3}{|c|}{ Description of the item/indicator } \\
\hline 1 & \multicolumn{3}{|c|}{ How often have you been upset because of something that happened unexpectedly? } \\
\hline 2 & \multicolumn{3}{|c|}{ How often have you felt that you were unable to control the important things in your life? } \\
\hline 3 & \multicolumn{3}{|c|}{ How often have you felt nervous and "stressed"? } \\
\hline 4 & \multicolumn{3}{|c|}{${ }^{*}$ How often have you felt confident about your ability to handle your personal problems? } \\
\hline 5 & \multicolumn{3}{|c|}{${ }^{*}$ How often have you felt that things were going your way? } \\
\hline 6 & \multicolumn{3}{|c|}{ How often have you found that you could not cope with all the things that you had to do? } \\
\hline 7 & \multicolumn{3}{|c|}{${ }^{*}$ How often have you been able to control irritations in your life? } \\
\hline 8 & \multicolumn{3}{|c|}{${ }^{*}$ How often have you felt that you were on top of things? } \\
\hline 9 & \multicolumn{3}{|c|}{ How often have you been angered because of things that happened that been outside of your control? } \\
\hline 10 & \multicolumn{3}{|c|}{ How often have you felt difficulties were piling up so high that you could not overcome them? } \\
\hline \multicolumn{4}{|c|}{ * denotes positively worded items. } \\
\hline Sr. No. & Instrument & No. of items & Cronbach's alpha value \\
\hline 1 & Instrument for Perceived Stress (Cohen's PSS-10) & 10 & 0.741 \\
\hline 2 & Instrument for antecedents (APS) & 34 & 0.921 \\
\hline 3 & Instrument for consequences (CPS) & 22 & 0.940 \\
\hline
\end{tabular}

TABLE 4: Kaiser-Meyer-Olkin (KMO) and Bartlett's test.

\begin{tabular}{lccc}
\hline & & For antecedents & For consequences \\
\hline Kaiser-Meyer-Olkin measure of sampling adequacy & Approx. Chi-square & 0.917 & 0.968 \\
& df & 52029.411 & 39108.072 \\
Bartlett's test of sphericity & Sig. & 561 & 231 \\
& & 0.0001 & 0.0001 \\
\hline
\end{tabular}

TABle 5: Components for the antecedents and consequences of work stress.

Antecedents (APS) (total variance explained 70.6\%) Consequences (CPS) (total variance explained 67.2\%)

\begin{tabular}{|c|c|c|c|c|c|c|c|}
\hline Sr. no. & Component name & No. of items & Variance explained & Sr. no. & $\begin{array}{c}\text { Component } \\
\text { name }\end{array}$ & No. of items & Variance explained \\
\hline 1 & Work-family conflict & 5 & 28.977 & 1 & Psychological & 7 & 45.746 \\
\hline 2 & Role clarity & 3 & 11.160 & 2 & Emotional & 3 & 6.497 \\
\hline 3 & Managers' support at work & 3 & 5.513 & 3 & Performance & 4 & 6.219 \\
\hline 4 & Physical agents at work & 5 & 4.915 & 4 & Physical & 4 & 5.154 \\
\hline 5 & Social working environment & 4 & 4.310 & 5 & Behavioral & 2 & 3.564 \\
\hline 6 & Training and career development & 3 & 3.658 & & & & \\
\hline 7 & Control and decision latitude & 3 & 3.465 & & & & \\
\hline 8 & Hygienic conditions & 2 & 3.248 & & & & \\
\hline 9 & Work characteristics & 3 & 2.765 & & & & \\
\hline 10 & Working conditions & 3 & 2.548 & & & & \\
\hline
\end{tabular}

Initially, a threshold for factor loading as 0.70 with $p$ value $<0.05$ and $t$ value $>1.96$ was observed (Figure 1 and Table 7 ). A higher level of outer factor loading confirms a superior level of indicator reliability, as shown in Figure 1 and Table 7 $[61,62]$.

Afterward, the measures' internal consistency for all latent variables was also confirmed by computing the composite reliability and Cronbach's alpha values. Usually, in social sciences, the reliability of the instrument is tested through checking of inner consistency which is done by calculating the "Cronbach's alpha" values. However, in PLS-SEM, previous literature has recommended considering the value against "Composite Reliability" a substitute $[62,63]$. All the values of composite reliabilities and Cronbach's alpha are larger than 0.70 which confirms the reliability of the measures' internal consistency as well [54, 61, 63, 64] (Table 6).

Likewise, in establishing the validity of the constructs, discriminant validity and convergent validity were checked [65]. The convergent validity was measured construct-wise as well as item-wise. Subsistence of all the AVE (average variance explained) values greater than 0.50 (Table 6) indicates construct-wise convergent validity $[66,67]$, whereas 


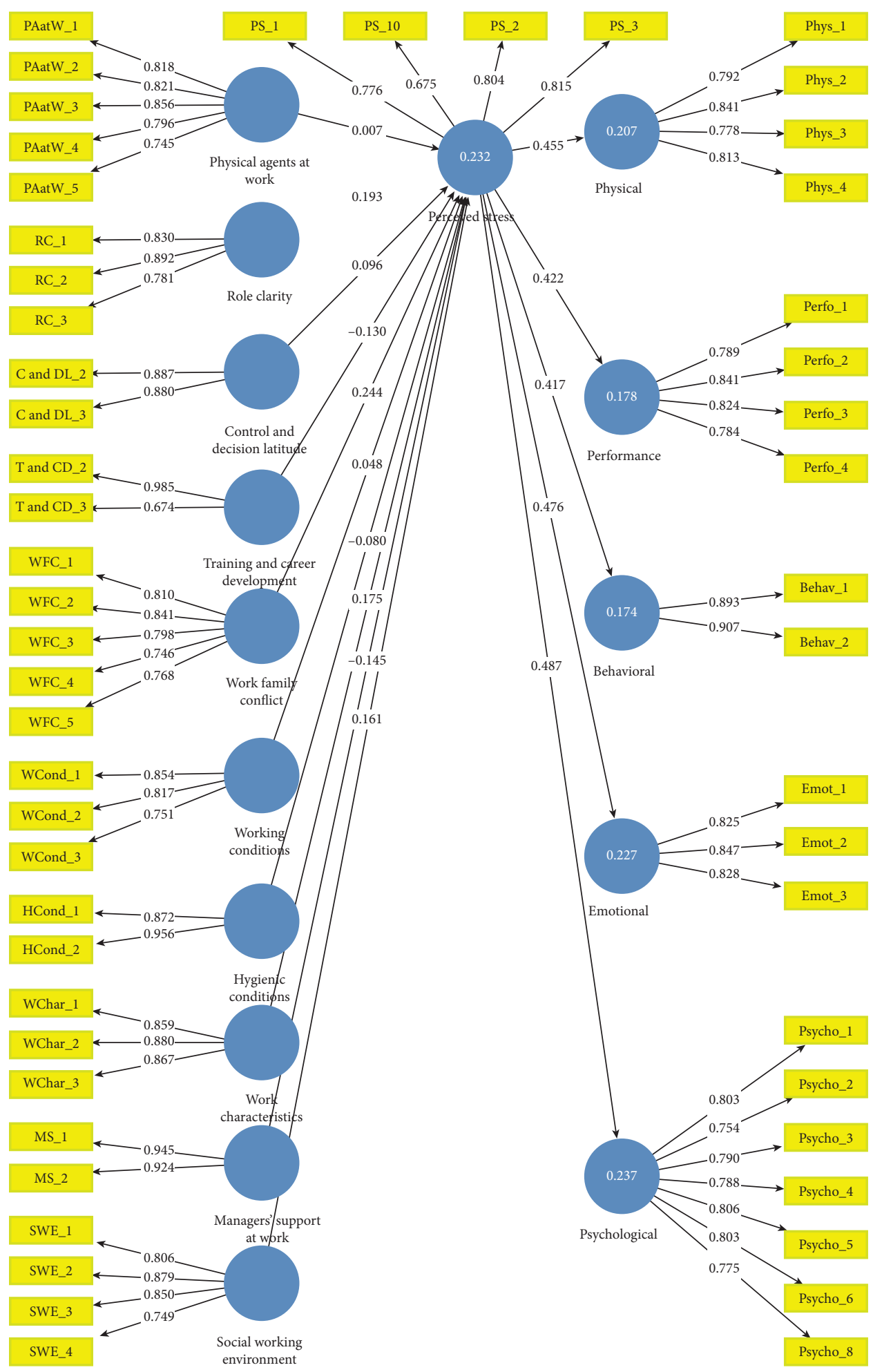

FIgURe 1: PLS structural equation modelling.

the existence of all the loading values greater than 0.70 (except one which is close to 0.70) confirm item-wise convergent validity (Figure 1 and Table 7) [68]. After successfully establishing the reliability as well as constructs' convergent validity, the constructs' discriminant validity was evaluated.
The discriminant validity evaluates the degree to which a construct is experimentally not quite the same as different constructs in the path model, both as far as the extent to it relates with some other constructs, regarding how markedly the indicators correspond to only this particular construct. In summary, discriminant validity confirms the distinctive 
TABLE 6: Results summary for latent variables.

\begin{tabular}{|c|c|c|c|c|c|}
\hline Latent variable & Composite reliability & Cronbach's alpha & AVE & $R$ square & Q square \\
\hline Behavioral (Behav) & 0.895 & 0.765 & 0.809 & 0.174 & 0.136 \\
\hline Control and decision latitude (C\&DL) & 0.877 & 0.720 & 0.781 & & \\
\hline Emotional (Emot) & 0.872 & 0.781 & 0.695 & 0.227 & 0.15 \\
\hline Hygienic conditions (HCond) & 0.911 & 0.817 & 0.837 & & \\
\hline Managers' support at work (MS) & 0.933 & 0.857 & 0.686 & & \\
\hline Perceived stress (PS) & 0.852 & 0.768 & 0.592 & 0.232 & 0.128 \\
\hline Performance (Perfo) & 0.884 & 0.825 & 0.656 & 0.178 & 0.111 \\
\hline Physical (Phys) & 0.881 & 0.821 & 0.650 & 0.207 & 0.127 \\
\hline Physical agents at work (PAatW) & 0.904 & 0.867 & 0.653 & & \\
\hline Psychological (Psycho) & 0.920 & 0.899 & 0.622 & 0.237 & 0.14 \\
\hline Role clarity (RC) & 0.874 & 0.786 & 0.698 & & \\
\hline Social working environment (SWE) & 0.893 & 0.839 & 0.676 & & \\
\hline Training and career development (T\&CD) & 0.828 & 0.701 & 0.713 & & \\
\hline Work characteristics (WChar) & 0.902 & 0.838 & 0.755 & & \\
\hline Work-family conflict (WFC) & 0.894 & 0.853 & 0.629 & & \\
\hline Working conditions (WCond) & 0.850 & 0.735 & 0.654 & & \\
\hline
\end{tabular}

TABLE 7: Latent variables, indicator/item name, item description, and loadings.

\begin{tabular}{|c|c|c|c|}
\hline Latent variable & $\begin{array}{l}\text { Indicator/Item } \\
\text { name }\end{array}$ & Item description & Loadings \\
\hline \multirow{5}{*}{ Physical agents at work (PAatW) } & PAatW_1 & Physical dangers exist in the workplace & 0.818 \\
\hline & PAatW_2 & My job requires me to touch potentially harmful substances or material & 0.821 \\
\hline & PAatW_3 & My job exposes me to breathing fumes, dust, or other harmful substances & 0.856 \\
\hline & PAatW_4 & $\begin{array}{l}\text { I have work tasks that leave me with a ringing in my ears or a feeling of } \\
\text { temporary deafness }\end{array}$ & 0.796 \\
\hline & PAatW_5 & $\begin{array}{l}\text { I work in an environment where the level of background noise disturbs } \\
\text { me }\end{array}$ & 0.745 \\
\hline \multirow{3}{*}{ Role clarity (RC) } & RC_1 & I am clear what my duties and responsibilities are & 0.830 \\
\hline & $\mathrm{RC} \_2$ & I am clear about what is expected of me at work & 0.892 \\
\hline & RC_3 & I know how to go about getting my job done & 0.781 \\
\hline \multirow{2}{*}{$\begin{array}{l}\text { Control and decision latitude } \\
\text { (C\&DL) }\end{array}$} & C\&DL_2 & I am clear what my duties and responsibilities are & 0.887 \\
\hline & C\&DL_3 & I am clear about what is expected of me at work & 0.880 \\
\hline \multirow{2}{*}{$\begin{array}{l}\text { Training and career development } \\
(\mathrm{T} \& \mathrm{CD})\end{array}$} & T\&CD_2 & There are enough development opportunities for me in this organization & 0.985 \\
\hline & T\&CD_3 & This organization is providing me with job-specific training & 0.677 \\
\hline \multirow{5}{*}{ Work-family conflict (WFC) } & WFC_1 & $\begin{array}{l}\text { My job takes up so much energy I do not feel up to doing things that need } \\
\text { attention at home }\end{array}$ & 0.810 \\
\hline & WFC_2 & Problems at work make me irritable at home & 0.840 \\
\hline & WFC_3 & My job does not allow me enough time for my family & 0.798 \\
\hline & WFC_4 & Family obligations reduce the time I need to relax & 0.746 \\
\hline & WFC_5 & Family worries or problems distract me from my work & 0.768 \\
\hline \multirow{3}{*}{ Working conditions (WCond) } & WCond_1 & The equipment which I work with is poorly maintained & 0.854 \\
\hline & WCond_2 & I have to work in inadequate lighting & 0.817 \\
\hline & WCond_3 & My workplace is too cold & 0.751 \\
\hline \multirow{2}{*}{ Hygienic conditions (HCond) } & HCond_1 & $\begin{array}{c}\text { I am worried about the "hygienic conditions" of food served at the canteen } \\
\text { of the workplace }\end{array}$ & 0.872 \\
\hline & HCond_2 & $\begin{array}{c}\text { I am worried about the "hygienic conditions" of drinking water at the } \\
\text { workplace }\end{array}$ & 0.956 \\
\hline \multirow{3}{*}{ Work characteristics (WChar) } & WChar_1 & I have to do the same thing over and over again & 0.859 \\
\hline & WChar_2 & I have to work very fast & 0.880 \\
\hline & WChar_3 & My workload is too heavy & 0.867 \\
\hline \multirow{2}{*}{ Managers' support at work (MS) } & MS_1 & I can rely on my line manager to help me out with a work problem & 0.945 \\
\hline & MS_2 & My line manager encourages me at work & 0.925 \\
\hline \multirow{4}{*}{$\begin{array}{l}\text { Social working environment } \\
\text { (SWE) }\end{array}$} & SWE_1 & I experience too much discrimination in the organization & 0.806 \\
\hline & SWE_2 & $\begin{array}{c}\text { I am subject to personal harassment in the form of unkind words or } \\
\text { behavior }\end{array}$ & 0.879 \\
\hline & SWE_3 & I am subject to bullying at work & 0.850 \\
\hline & SWE_4 & There is friction or anger between colleagues & 0.749 \\
\hline
\end{tabular}


TABLE 7: Continued.

\begin{tabular}{|c|c|c|c|}
\hline Latent variable & $\begin{array}{l}\text { Indicator/Item } \\
\text { name }\end{array}$ & Item description & Loadings \\
\hline \multirow{4}{*}{ Physical (Phys) } & Phys_1 & I Have felt tired & 0.792 \\
\hline & Phys_2 & I Have headaches & 0.841 \\
\hline & Phys_3 & $\begin{array}{l}\text { I get tension or muscle spasms/pains in my face, jaw, neck, chest, head, } \\
\text { lower back, or shoulders }\end{array}$ & 0.779 \\
\hline & Phys_4 & I lack physical energy & 0.813 \\
\hline \multirow{4}{*}{ Performance (Perfo) } & Perfo_1 & Often, I am unable to complete the task as per schedule & 0.789 \\
\hline & Perfo_2 & My judgment is clouded or not as good as it was & 0.841 \\
\hline & Perfo_3 & I am ineffective in resolving family issues & 0.824 \\
\hline & Perfo_4 & Usually, I am unable to do all the things in a day that I must do & 0.784 \\
\hline \multirow{3}{*}{ Behavioral (Behav) } & Behav_1 & $\begin{array}{c}\text { My appetite has been changed; I have either a desire to binge or have a loss } \\
\text { of appetite/may skip meals }\end{array}$ & 0.857 \\
\hline & Behav_2 & $\begin{array}{c}\text { I seem to be listening even though I am preoccupied with my own } \\
\text { thoughts }\end{array}$ & 0.882 \\
\hline & Behav_3 & I tend to eat, talk, walk, and drive quickly & 0.712 \\
\hline \multirow{3}{*}{ Emotional (emot) } & Emot_1 & I have become short-tempered & 0.825 \\
\hline & Emot_2 & I become very frustrated at having to wait in a queue & 0.847 \\
\hline & Emot_3 & I experience mood swings & 0.828 \\
\hline \multirow{7}{*}{ Psychological (Psycho) } & Psycho_1 & I suffer from frequent depression & 0.803 \\
\hline & Psychol_2 & I experience worsening relations with colleagues, family, and friends & 0.754 \\
\hline & Psycho_3 & I often suffer from sleeplessness & 0.790 \\
\hline & Psycho_4 & I used to avoid people & 0.788 \\
\hline & Psycho_5 & I often suffer from anger/hostility & 0.806 \\
\hline & Psycho_6 & I have had dizzy spells & 0.803 \\
\hline & Psycho_8 & I often suffer from anxiety & 0.775 \\
\hline \multirow{4}{*}{ Perceived stress (PS) } & PS_1 & $\begin{array}{l}\text { How often have you been upset because of something that happened } \\
\text { unexpectedly? }\end{array}$ & 0.776 \\
\hline & PS_2 & $\begin{array}{c}\text { How often have you felt that you were unable to control the important } \\
\text { things in your life? }\end{array}$ & 0.804 \\
\hline & PS_3 & How often have you felt nervous and "stressed"? & 0.815 \\
\hline & PS_10 & $\begin{array}{l}\text { How often have you felt difficulties were piling up so high that you could } \\
\text { not overcome them? }\end{array}$ & 0.674 \\
\hline
\end{tabular}

conception of items and their constructs [69]. Subsequently, the discriminant validity of the constructs was assessed. It was measured construct-wise as well as items-wise. The Fornell-Larcker [70] criterion, the most conservative method, was used in evaluating construct-wise discriminant validity. According to the Fornell-Larcker [70] criterion, the square root of the AVE of each construct should be higher than its highest correlation with any other construct. As shown in Appendix B in Supplementary Materials, higher values at the diagonal confirm the fulfillment of the Fornell-Larcker criterion. Another approach in assessing discriminant validity is "Cross-Loadings" which was also examined. Accordingly, as shown in Appendix D in Supplementary Materials, the existence of greater item loading on the constructs to which they belong than to other constructs confirms the item-wise discriminant validity as well [71].

Discriminant validity assessment in PLS-SEM also involves analyzing HTMT (heterotrait-monotrait ratio) of correlations. In this method, heterotrait-monotrait ratio (HTMT) of the correlations is examined [72]. It is given that big HTMT values show issues with the discriminant validity. In the light of earlier research and their simulation contemplate results, Henseler et al. [73] recommend an edge estimation of 0.90 in case the path model comprises constructs that are theoretically much alike (e.g., cognitive satisfaction, affective satisfaction, and loyalty); that is to say, in this circumstance, an HTMT value surpassing 0.90 proposes an absence of discriminant validity. Notwithstanding, when the builds in the path model are theoretically diverse, researchers ought to consider 0.85 as the limit for HTMT [73]. Here, as shown in Appendix C in Supplementary Materials, all the values were found within the threshold of 0.85 . Consequently, the discriminant validity was confirmed this way as well.

The evaluation of the model's quality concerning its potentiality to envisage the endogenous constructs was also confirmed through cross-validated redundancy $\left(Q^{2}\right)$ and coefficient of determination $\left(R^{2}\right)$ values. According to the recommended values, $R^{2}$ values are higher than 0.2 , while $Q^{2}$ values were greater than zero as provided in Table $6[63,74-76]$. The model was also tested for the potential multicollinearity issue among the predictors. The VIF values within the threshold (0.5) confirmed that there was no issue of multicollinearity [77].

4.2.2. Testing Path Model. In testing the path model, this research study utilized Smart PLS3 release 3.2.8 [57] as depicted in Figure 1. The bootstrapping procedure used data 
of 1470 participants and 1,000 samples. In deploying PLSSEM analyses and thereupon disclosing the findings, recent guidelines for PLS-SEM given by Hair et al. [77], Hair et al. [63], and Hair et al. [61] were considered. As mentioned in the preceding section, the measurement models were weighed up before evaluating the structural model.

The path is considered to be significant if the $T$ statistics is above 1.96 using a two-tailed $t$ test under $5 \%$ significance level [61]. Table 6 demonstrates the nonsignificance of the paths' physical agents at work $\longrightarrow$ perceived stress and working conditions $\longrightarrow$ perceived stress having $p$ values 0.825 and 0.124 , respectively. In the inner model, all other path coefficients are statistically significant and have $T$ statistics greater than 1.96, yet control and decision latitude $\longrightarrow$ perceived stress and hygienic conditions $\longrightarrow$ perceived stress having beta values 0.096 and 0.080 (less than 0.10), respectively, indicate weak relationships.

Amongst the antecedents, work-family conflict is the most significant component (Table 5) and the results of the path analysis have validated the findings of the EFA. The component work-family conflict has the highest beta value (0.244) among the components of antecedents (Table 8) and thus showed a strong and significant positive correlation with the dependent variable, i.e., perceived stress. The results of the examination disclose that if other aspects remain constant, with one unit increase in work-family conflict, perceived stress will increase by 0.244. Likewise, according to EFA results, the component working condition is the least significant (Table 5); path analysis results revealed its relationship as nonsignificant. However, for the component physical agents at work, the EFA results and path analysis results are not aligned. The component, according to EFA, is the fourth significant (Table 5) while, according to path analysis, its relationship with the dependent variable (perceived stress) is nonsignificant (Table 8). In context to their EFA and path analysis results, the rest of the components of antecedents are more or less aligned up.

In case of consequences, the results, EFA and path analysis, are exactly in the same order except for one situation that is between performance effects and physical effects. The component psychological effect, as per EFA results, is the most significant (Table 5). Having beta value 0.487 and $p$ value 0.0001 , the path of the component with the dependent variable (perceived stress) is significant and most strong (Table 8). The results of the examinations about consequences reveal that if other variables remain constant, one unit increment in perceived stress will increase the psychological effect by 0.487 , emotional effect by 0.476 , physical effect by 0.455 , performance effect by 0.422 , and behavioral effect by 0.417 .

On the basis of the analysis, the hypotheses build in the second phase of this case study and placed in the proposed hypothetical model section can be concluded as shown in Table 9.

\section{Discussion}

The objectives of this study were to determine the antecedents and consequences of work stress among the employees of the textile sector organization in Pakistan $(N=1470)$ and also to investigate the relationships of the antecedents and the perceived stress and the relationship of the perceived stress with the consequences. Stress literature on the textile sector is scarce, and even the available literature does not cover the sector as a whole. For example, Steinisch et al. [78] worked on a single garment factory with a limited sample of 332. On the contrary, the present study provides a more comprehensive investigation of stress phenomena among the employees of textile industries as this covers almost all areas of the textile sector (fiber/cloth manufacturing, home textiles, apparel manufacturing, and sock manufacturing) with a substantial sample size (1470) belonging to 24 diverse companies. Additionally, this not only identifies antecedents and consequences of stress in the sector but also highlights how they are associated with the employees' perceived stress. According to the relational findings of the antecedents, work-family conflict $(\beta=0.0 .244$ and $p=0.0001)$ has the highest impact on the perceived stress followed by role clarity $(\beta=0.193$ and $p=0.0001)$, work characteristics $(\beta=0.176$ and $p=0.0001)$, and social working environment $(\beta=0.161$ and $p=0.0001)$. Similarly, among the outcomes of work stress, psychological $(\beta=0.487$ and $p=0.0001$ ) has the highest effect of the perceived stress on the subjects followed by emotional $(\beta=0.476$ and $p=0.0001)$, physical $(\beta=0.455$ and $p=0.0001)$, and performance $(\beta=0.422$ and $p=0.0001)$ effects. There were seven items in the component psychological. The items, in order of their strength, are Psycho_5: I often suffer from anger/hostility, Psycho_1: I suffer from frequent depression, Psycho_6: I have had dizzy spells, Psycho_3: I often suffer from sleeplessness, Psycho_4: I used to avoid people, Psycho_8: I often suffer from anxiety, and Psycho_1: I experience worsening relations with colleagues, family, and friends (Figure 1 and Table 7).

Multiple studies have been carried out in identifying the antecedents of work stress in general. In a study on a limited sample of managers of the textile industry in Pakistan, support at work, the work-family interface, social working environment, and role were identified as the potential factors for the antecedents of work stress amongst physical agents at work, and social working environment were found to be positively and strongly correlated with work stress $[3,79]$. The present study, carried out on a large sample size from T\&C sector employees, revealed a social working environment as an antecedent where workplace bullying [30] is one of its indicators (Table 3). A study carried out at a manufacturing plant revealed that work-family conflict and abusive supervision were positively correlated with unsafe commuting behavior [80] which is the impact of stress [81]. Work-family conflict is the most significant antecedent of stress in the present study. The current research has supported almost all the stressors, namely, role ambiguity, work overload, career development, working relationship, and working environment found in the study on industrial zone employees of Vietnam [33]. Work overload, work environment, and workfamily conflict were also found as stressors for working mothers in Pakistan [82]. In a study on employees of the UK and Pakistan, organizational factors were found as stress 
TABle 8: Path coefficients retrieved from bootstrapping procedure.

\begin{tabular}{|c|c|c|c|c|c|c|}
\hline Structural path & $\begin{array}{c}\text { Original } \\
\text { sample }(\mathrm{O})\end{array}$ & $\begin{array}{l}\text { Sample mean } \\
\text { (M) }\end{array}$ & $\begin{array}{l}\text { Standard deviation } \\
\text { (STDEV) }\end{array}$ & $\begin{array}{l}\text { T statistics } \\
(|\mathrm{O} / \mathrm{STDEV}|)\end{array}$ & $\begin{array}{c}p \\
\text { values }\end{array}$ & $\begin{array}{c}\mathrm{f} \\
\text { square }\end{array}$ \\
\hline $\begin{array}{l}\text { Physical agents at work } \longrightarrow \text { perceived } \\
\text { stress }\end{array}$ & 0.007 & 0.006 & 0.033 & 0.221 & 0.825 & 0.0001 \\
\hline Role clarity $\longrightarrow$ perceived stress & 0.193 & 0.191 & 0.03 & 6.491 & 0.0001 & 0.037 \\
\hline $\begin{array}{l}\text { Control and decision } \\
\text { latitude } \longrightarrow \text { perceived stress }\end{array}$ & 0.096 & 0.093 & 0.03 & 3.244 & 0.001 & 0.009 \\
\hline $\begin{array}{l}\text { Training and career } \\
\text { development } \longrightarrow \text { perceived stress }\end{array}$ & -0.13 & -0.112 & 0.042 & 3.076 & 0.002 & 0.015 \\
\hline Work-family conflict $\longrightarrow$ perceived stress & 0.244 & 0.241 & 0.038 & 6.468 & 0.0001 & 0.038 \\
\hline Working conditions $\longrightarrow$ perceived stress & 0.048 & 0.047 & 0.031 & 1.538 & 0.124 & 0.002 \\
\hline Hygienic conditions $\longrightarrow$ perceived stress & -0.08 & -0.081 & 0.033 & 2.422 & 0.016 & 0.005 \\
\hline Work characteristics $\longrightarrow$ perceived stress & 0.176 & 0.173 & 0.036 & 4.869 & 0.0001 & 0.023 \\
\hline $\begin{array}{l}\text { Managers' support at work } \longrightarrow \text { perceived } \\
\text { stress }\end{array}$ & -0.146 & -0.146 & 0.04 & 3.618 & 0.0001 & 0.018 \\
\hline $\begin{array}{l}\text { Social working environment } \longrightarrow \text { perceived } \\
\text { stress }\end{array}$ & 0.161 & 0.161 & 0.035 & 4.586 & 0.0001 & 0.018 \\
\hline Perceived stress $\longrightarrow$ physical effect & 0.455 & 0.455 & 0.025 & 18.133 & 0.0001 & 0.261 \\
\hline Perceived stress $\longrightarrow$ performance effect & 0.422 & 0.423 & 0.028 & 15.231 & 0.0001 & 0.217 \\
\hline Perceived stress $\longrightarrow$ emotional effect & 0.476 & 0.476 & 0.022 & 21.248 & 0.0001 & 0.293 \\
\hline Perceived stress $\longrightarrow$ behavioral effect & 0.417 & 0.418 & 0.025 & 16.478 & 0.0001 & 0.211 \\
\hline Perceived stress $\longrightarrow$ psychological effect & 0.487 & 0.488 & 0.025 & 19.666 & 0.0001 & 0.310 \\
\hline
\end{tabular}

TABLE 9: Results of the hypothesis build for the case study.

\begin{tabular}{|c|c|}
\hline Hypothesis & Conclusion \\
\hline H1.1: existence of the physical hazards at the workplace is positively correlated with the work stress & Rejected \\
\hline H1.2: absence of role clarity is positively correlated with the work stress & Accepted \\
\hline H1.3: absence of control and decision latitude among the employees is positively linked with the work stress & Rejected \\
\hline H1.4: dearth of career development and training of the employees is positively related to the workplace stress & Accepted \\
\hline H1.5: work-family conflict is positively related with work stress & Accepted \\
\hline H1.6: & Rejected \\
\hline H1.7: poor hygienic $\mathrm{c}$ & Rejected \\
\hline H1. & Accepted \\
\hline $\mathrm{H} 1$. & Accepted \\
\hline H1.10: p & Accepted \\
\hline ical effects" on th & Accepted \\
\hline ployees' perfor & Accepted \\
\hline $\mathrm{H} 2.3$ & Accepted \\
\hline $\mathrm{H} 2.4$ : & Accepted \\
\hline H2.5: the impact of wo & Accepted \\
\hline
\end{tabular}

antecedents for male employees while personal factors for females [83]. In another study, "organizational constraints" (OCs) were found as a unique stressor [84] besides personal situations, tasks, organizational settings, and physical conditions, [36] which, evidently, are OCs, and in the present study, the components role ambiguity and work characteristics found among the significant components also belong to OCs. Similarly, in a study on the employees of a garment factory in Bangladesh, "high work-related demands" and "poor interpersonal communication" were found as the critical stress components. The significant indicators were time pressure and support, respectively, while "work-related values" was nonsignificant indicator; freedom was also among the indicators [78]. The present study has supported all three indicators in the same order: the heavy workload is one of the indicators of a significant component work characteristics yielding workload as a stressor. Poor economic conditions might be one of the reasons behind the heavy workload as most of the employees used to work for extra time so that they could manage their livelihood. This "working for overtime phenomenon" is not only contributing to their stress level but also adversely affecting their family lives and giving rise to the work-family conflict which in our study has appeared as the most significant antecedent of stress.

Likewise, in a meta-analysis performed by Pindek and Spector [84], behavioral, physical, and psychological factors, consistent with the present study, were found as the outcomes of stress. A study on a limited sample of managers of textile sector organizations in Pakistan, revealed physical, psychological, behavioral, performance, and physiological as the potential factors for the consequences of work stress [85]. The present study carried out on a big sample size of the T\&C sector employees, supported all the same factors except physiological. Secondly, the order of factors is different. Contrarily, psychological is the most significant stress component of the present study; a big difference in the 
sample sizes might be a reason behind diversity in the results. Ashong et al. [42] found tiredness as a stressor; it is one of the indicators of physical effects identified in the present study. In some earlier studies, decreased efficiency, reduced capacity to work, and diminished zeal [3, 37-39] were found as the consequences of stress. These items relate to the factor performance effects identified in the present study.

5.1. Practical Implications. This research concludes that work stress is a complex phenomenon, which is linked with multiple causes in the T\&C sector and has serious implications for individuals and organizations. As this research provides necessary information about the antecedents and consequences, interventions can be designed accordingly in addressing these issues proactively. In this respect, the design and implementation of related interventions can be inculcated through better understanding and awareness among the stakeholders, mainly employees and managers.

Thus, the findings of the study can help managers, designers, planners, and ergonomists in making more informed and proactive decisions while attempting to prevent or control the stress phenomenon in the T\&C sector. Specifically, the results of this study would provide an opportunity to understand the role of different factors such as work-family conflict, training and development needs of the employees, role clarity, physical agents, and management support in the context of the work-stress phenomenon. In this way, these insights could help managers in the dissemination of decisions, aiming at addressing these issues at some earlier decision-making stages. Moreover, this research also provides information regarding the consequences of work stress in the $\mathrm{T} \& \mathrm{C}$ sector. Therefore, the outcomes help raise awareness about the consequences of employees' stress at work, and their implications for the organization, especially the reduced performance at the workplace.

5.2. Limitations and Future Research. To carry out very comprehensive research on such a complex issue has been a challenging job. In spite of valuable contributions in the area of work-stress management, certainly this research has some limitations. For example, information gathering from the participants has been a much difficult area in the study. In certain cases, the employers did not allow them to conduct the study in their organizations. Access to the employees for data collection has been a major limitation of the study. Therefore, the sample used in the study, up to the extent of organization selection, is based on convenient sampling so the generalizability of the results is limited. Further investigations might be carried out by employing probability-based sampling so that more generalized conclusions could be made. As the data was collected from the textile industry in Pakistan, so the findings might not be the same for other regions because of changing organizational settings, policies, procedures, and culture. Further investigations might be done in other sectors and comparisons could be made. Stress management is the area where the research activities should be continued. A subsectorfocused and even organization-focused research is recommended as a future work where both quantitative and qualitative data collection should be carried out on the causes, effects of work stress, and also on the proposed interventions which is the ultimate goal of stress management. Future research can be designed to explore the stress management interventions where the objective should be to reduce the antecedents identified in the present study. Future studies should employ probability-based sampling techniques even in the selection of organizations. Ikram et al. [86] suggested that the traditional textile sector should be developed through proper governance framework such as triple helix model, so future researchers are advised to investigate the implication of such governance frameworks in the context of textile sector of Pakistan.

\section{Conclusion}

This cross-sectional research aimed at investigating the antecedents and consequences of work stress and also their association with the perceived stress among employees of T\&C sector organizations. For this purpose, data were collected from 1470 employees of 24 related organizations. Cohen's PSS-10 was used to gauge the level of perceived stress of the subjects, while researcher-developed instruments were used to gather data for the identification of antecedents and consequences. Mainly, EFA and PLS-SEM were employed on the information gathered. EFA identified ten components for the antecedents and five components for the consequences of stress, while PLS-SEM yielded six antecedents to have a not only significant but also a strong effect on the perceived stress, which, in turn, was having a significant and strong impact on all the five consequences. The antecedents in order of their strength are work-family conflict, role clarity, work characteristics, social working environment, managers' support at work, and training and career development, whereas the consequences in the same order are psychological, emotional, physical, performance, and behavioral. Taking into account the antecedents identified, the conflicts between work and family affairs, issues about the clarity of employees' roles in the workplaces, workload, completion deadlines, task repetitiveness, bullying and discrimination, training and career development, and lack of managers' support need to be addressed in managing the stress of employees. In the dearth of such studies, especially in the T\&C sector, the findings of the study are expected to help managers, designers, planners, and ergonomists in taking more informed and proactive decisions that are likely to be more effective for a broader range of the working population. Moreover, the study further highlights the need for gaining a somewhat more indepth insight into the work stress phenomenon proactively so that the effectiveness of intervention strategies might be assured. This study provides a good insight into the complexity of the stress phenomenon and can be linked with similar kinds of working environments.

\section{Data Availability}

The data used to support the findings of this study are available from the corresponding author upon request. 


\section{Conflicts of Interest}

The authors declare that there are no conflicts of interest regarding the publication of this paper.

\section{Authors' Contributions}

Aftab Ahmad and Amjad Hussain conceptualized the study. Aftab Ahmad, Asif Mahmood, and Ayyaz Ahmad developed the methodology. Aftab Ahmad and Shagufta Yasmin collected data and carried out field visits. Aftab Ahmad, Asif Mahmood, Ayyaz Ahmad, and Amir Ikram validated and analysed the study. Aftab Ahmad, Amjad Hussain, and Amir Ikram wrote the original draft. Shagufta Yasmin and Amir Ikram wrote the revised draft.

\section{Acknowledgments}

The cooperation of the industry in information gathering is acknowledged.

\section{Supplementary Materials}

Appendix A (survey instrument): the questionnaire was used for the operationalization of the study and data collection. Appendix B: discriminant validity (construct-wise) retrieved from "Fornell-Larcker criterion." Appendix C: heterotraitmonotrait ratio (HTMT) of correlations. Appendix D: cross loadings for assessing discriminant validity. (Supplementary Materials)

\section{References}

[1] A. Mahmood, "Smart lean in ring spinning-a case study to improve performance of yarn manufacturing process," The Journal of The Textile Institute, vol. 112, no. 1, pp. 1-16, 2020.

[2] T.-M. Choi, X. Yue, C.-H. Chiu, and P.-S. Chow, "Mathematical modeling research in fashion and textiles supply chains and operational control systems," Mathematical Problems in Engineering, vol. 2013, Article ID 470567, 4 pages, 2013.

[3] A. Ikram and Q. Su, "Determinants of productivity in the ready-made garments SMEs of Lahore, Pakistan," in Proceedings of the 5th International Asia Conference on Industrial Engineering and Management Innovation (IEMI2014), pp. 81-86, Xi'an, China, February 2015.

[4] Z. Cheng, J. Xiao, K. Xie, and X. Huang, "Optimal product quality of supply chain based on information traceability in fashion and textiles industry: an adverse logistics perspective," Mathematical Problems in Engineering, vol. 2013, Article ID 629363, 13 pages, 2013.

[5] J. Keane and D. W. te Velde, The Role of Textile and Clothing Industries in Growth and Development Strategies, Overseas Development Institute (ODI), London, UK, 2008.

[6] A. Mahmood, "Gazing lean through the lens of system of systems dynamics: a case of weaving mill," Journal of Engineered Fibers and Fabrics, vol. 14, no. 1, pp. 1-16, 2019.

[7] APTMA, "Textile industry's economic contribution, all Pakistan textile mills association," 2016, http://www.aptma. org.pk/Pak_Textile_Statistics/tec/ASP.

[8] C.-N. Wang, H.-K. Nguyen, and R.-Y. Liao, "Partner selection in supply chain of vietnam's textile and apparel industry: the application of a hybrid DEA and GM $(1,1)$ approach," Mathematical Problems in Engineering, vol. 2017, Article ID 7826840, 16 pages, 2017.

[9] A. A. Ali, A. Mahmood, A. Ahmad, and A. Ikram, "Boosting up operational performance of manufacturing organizations through interpretive structural modelling of enabling practices," Mathematical Problems in Engineering, vol. 2020, Article ID 8645343, 2020.

[10] ILO, ILO Calls for Improved ILS Compliance in the Garment and Textile Sector (Press Release), International Labor Organization, Genève, Switzerland, 2014.

[11] VicHealth, Creating Healthy Workplace . Final Report: Reducing Workplace Stress, VicHealth, Melbourne, Australia, 2016.

[12] European Foundation, 4th European Working Conditions Survey, European Foundation for the Improvement of Living and Working Conditions, Dublin, Ireland, 2007.

[13] American Psychological Association, Stress in the Workplace, American Psychological Association, Washington, D.C., USA, 2011, https://www.apa.org/news/press/releases/phwasurvey-summary.pdf.

[14] R. Arnold, D. Fletcher, and K. Daniels, "Organisational stressors, coping, and outcomes in competitive sport," Journal of Sports Sciences, vol. 35, no. 7, pp. 694-703, 2017.

[15] P. L. Kitronza and P. Mairiaux, "Occupational stress among textile workers in the democratic republic of Congo," Tropical Medicine and Health, vol. 43, no. 4, pp. 223-231, 2015.

[16] H. Selye, "A syndrome produced by diverse nocuous agents," Nature, vol. 138, no. 3479, p. 32, 1936.

[17] H. Selye, The Stress of Life, McGraw-Hill Book Company, New York, NY, USA, 1956.

[18] D. P. Lumsden, "Is the concept of "stress" of any use, anymore?," in Contributions to Primary Prevention in Mental Health: Working Papers, D. Randall, Ed., Toronto Natl. Off. Canadian Mental Health Association, Toronto, Canada, 1981.

[19] T. Cox and A. Griffiths, "The nature and measurement of work stress: theory and practice," in Evaluation of Human Work: A Practical Ergonomics Methodology, J. R. Corlett, Ed., Taylor and Francis, London, UK, 3rd edition, 1995.

[20] R. S. Lazarus, Psychological Stress and the Coping Process, McGraw-Hill, New York, NY, USA, 1966.

[21] R. S. Lazarus and S. Folkman, Stress, Appraisal, and Coping, Springer, New York, NY, USA, 1984.

[22] T. Cox, Stress, MacMillian Press, London, UK, 1978.

[23] T. Cummings and C. L. Cooper, "A cybernetic framework for the study of occupational stress," Human Relations, vol. 32, pp. 345-419, 1979.

[24] J. Arnold, C. L. Cooper, and I. T. Robertson, Work Psychology: Understanding Human Behaviour in the Work Place, Pitman, Ed., Financial Times, London, UK, 1998.

[25] P. Dewe, "The appraisal process: exploring the role of meaning, importance, control and coping in work stress," Anxiety, Stress, \& Coping, vol. 5, no. 1, pp. 95-109, 1992.

[26] R. S. Lazarus, “Theory-based stress measurement," Psychological Inquiry, vol. 1, no. 1, pp. 3-13, 1990.

[27] R. S. Lazarus, Emotion and Adaptation, Oxford University Press, New York, NY, USA, 1991.

[28] S. Cohen, T. Kamarck, and R. Mermelstein, "A global measure of perceived stress," Journal of Health and Social Behavior, vol. 24, no. 4, pp. 385-396, 1983.

[29] V. Bruk-Lee, A. E. Nixon, and P. E. Spector, "An expanded typology of conflict at work: task, relationship and non-task organizational conflict as social stressors," Work \& Stress, vol. 27, no. 4, pp. 339-350, 2013. 
[30] S. Einarsen and M. B. Nielsen, "Workplace bullying as an antecedent of mental health problems: a five-year prospective and representative study," International Archives of Occupational and Environmental Health, vol. 88, no. 2, pp. 131-142, 2015.

[31] L. Björk, E. Bejerot, N. Jacobshagen, and A. Härenstam, "I shouldn't have to do this: illegitimate tasks as a stressor in relation to organizational control and resource deficits," Work \& Stress, vol. 27, no. 3, pp. 262-277, 2013.

[32] N. K. Semmer, N. Jacobshagen, L. L. Meier et al., "Illegitimate tasks as a source of work stress," Work \& Stress, vol. 29, no. 1, pp. 32-56, 2015.

[33] M. N. Khuong and V. H. Yen, "Investigate the effects of job stress on employee job performance - a case study at dong xuyen industrial zone, Vietnam," International Journal of Trade, Economics and Finance, vol. 7, no. 2, pp. 31-37, 2016.

[34] N. Shah, F. Abbas, Y. Abbas et al., "Assessment of the workplace conditions and health and safety situation in chemical and textile industries of Pakistan," Science Journal of Public Health, vol. 3, no. 6, pp. 857-864, 2015.

[35] M. K. Tucker, N. L. Jimmieson, and T. P. Oei, "The relevance of shared experiences: a multi-level study of collective efficacy as a moderator of job control in the stressor-strain relationship," Work \& Stress: An International Journal of Work, Health \& Organisations, vol. 27, no. 1, pp. 1-21, 2013.

[36] S. Senaratne and V. Rasagopalasingam, "The causes and effects of work stress in construction project managers: the case in Sri Lanka," International Journal of Construction Management, vol. 17, no. 1, pp. 65-75, 2017.

[37] J. Adriaenssens, D. Veronique, and S. Maes, "Causes and consequences of occupational stress in emergency nurses, a longitudinal study," Journal of Nursing Management, vol. 23, no. 3, pp. 346-382, 2015.

[38] R. Bridger, A. Day, and K. Mortan, "Occupational stress and employees turnover," Ergonomics, vol. 56, no. 11, pp. 1629-1639, 2013.

[39] S. Choi, J. Lee, and H. Park, "The effects of Psychological problems in employees' stress, self-esteem, and organizational commitment: the case of South Korean workplaces," Journal of Workplace Behavioural Health, vol. 30, no. 1, pp. 179-190, 2015.

[40] M. I. Qureshi, M. Iftikhar, S. G. Abbas, U. Hassan, K. Khan, and K. Zaman, "Relationship between job stress, workload, environment and employees turnover intentions: what we know, what should we know," World Applied Sciences Journal, vol. 23, no. 6, pp. 764-770, 2013.

[41] L. Toussaint, G. S. Shield, G. Dorn, and G. M. Slavich, "Effects of lifetime stress exposure on mental and physical health in young adulthood: how stress degrades and forgiveness protects health," Journal of Health Psychology, vol. 21, no. 6, pp. 1004-1014, 2014.

[42] G. Ashong, H. Rogers, B. Botwe, and S. Anim-Sa, "Effects of occupational stress and coping mechanisms adopted by radiographers in Ghana," Radiography, vol. 22, no. 2, pp. 112-117, 2015.

[43] M. L. Leisa, A. Allison, D. Nykamp, and S. Lanke, "Perceived stress and quality of life among doctor of pharmacy students," American Journal of Pharmaceutical Education, vol. 72, no. 6, p. 137, 2009.

[44] A. D. Turner, B. D. James, A. W. Capuano, N. T. Aggarwal, and L. L. Barnes, "Perceived stress and cognitive decline in different cognitive domains in a cohort of older African Americans," The American Journal of Geriatric Psychiatry, vol. 25, no. 1, pp. 25-34, 2016.
[45] G. Mark and A. P. Smith, "Effects of occupational stress, job characteristics, coping, and attributional style on the mental health and job satisfaction of university employees," Anxiety, Stress, \& Coping, vol. 25, no. 1, pp. 63-78, 2012.

[46] U. R. Srivastava, "Shift work related to stress, health and mood states: a study of dairy workers," Journal of Health Management, vol. 12, no. 2, pp. 173-200, 2010.

[47] M. H. Lawless, K. A. Harrison, G. A. Grandits, L. E. Eberly, and S. S. Allen, "Perceived stress and smoking-related behaviors and symptomatology in male and female smokers," Addictive Behaviors, vol. 51, pp. 80-83, 2015.

[48] Í. J. Ribeiro, R. Pereira, I. V. Freire, B. G. de Oliveira, C. A. Casotti, and E. N. Boery, "June). Stress and quality of life among university students: a systematic literature review," Health Professions Education, vol. 4, no. 2, pp. 70-77, 2018.

[49] S. Cohen and G. Williamson, "Perceived stress in probability sample of the United States," in The Social Psychology of Health: Claremont Symposium on Applied Social PsychologySage, Newbury Park, CA, USA, 1988.

[50] A. Ahmad, A. Hussain, M. Mughal, N. Mufti, and M. Saleem, "Workplace stress assessment among managers of textile industries at developing countries: a case study from Pakistan," in Advances in Intelligent Systems and Computing (Advances in Human Factors, Business Management and Leadership, AHFE 2017, B. T. Kantola J, Ed., Springer, Cham, Switzerland, pp. 382-391, 2018.

[51] S. Cohen, D. Janicki-Deverts, and G. E. Miller, "Psychological stress and disease," Journal of the American Medical Association, vol. 298, pp. 1685-1687, 2007.

[52] A. Kizhakkeveettil, A. M. Vosko, M. Brash, and A. M. Philips, "Perceived stress and fatigue among students in a doctor of chiropractic training program," Journal of Chiropractic Education, vol. 31, no. 1, pp. 8-13, 2017.

[53] A. Ahmad, A. Hussain, M. P. Mughal, N. A. Mufti, and M. Q. Saleem, "Perceived stress: role and levels of demographics - a cross-sectional study of textile industry employees," Industria Textila, vol. 71, no. 2, pp. 180-185, 2020.

[54] A. Field, Discovering Statistics Using SPSS, Sage Publications, London, UK, 2nd edition, 2005.

[55] P. Trivellas, P. Reklitis, and C. Platis, "The effect of job related stress on employees' satisfaction: a survey in Health Care," 2nd International Conference on Integrated Information, vol. 73, pp. 718-726, 2013.

[56] J. Pienaar and S. Rothmann, "Occupational stress in the South African police service," SA Journal of Industrial Psychology, vol. 32, no. 3, pp. 72-78, 2006.

[57] C. M. Ringle, “3.2.8," 2018, https://www.smartpls.com/ downloads.

[58] C. A. Cerny and H. F. Kaiser, "A study of a measure of sampling adequacy for factor-analytic correlation matrices," Multivariate Behavioral Research, vol. 12, no. 1, pp. 43-47, 1977.

[59] M. S. Bartlett, "The effect of standardization on a Chi-square approximation in factor analysis," Biometrika, vol. 38, no. 3/4, pp. 337-344, 1951.

[60] C. M. Ringle, S. Wende, and J. M. Becker, “SmartPLS 3," 2015.

[61] J. F. Hair, C. M. Ringle, and M. Sarstedt, "PLS-SEM: indeed a silver bullet," Journal of Marketing Theory and Practice, vol. 19, no. 2, pp. 139-151, 2011.

[62] J. F. Hair Jr., C. M. Ringle, and M. Sarstedt, "Partial least squares structural equation modeling: rigorous applications, better results and higher acceptance," Long Range Planning, vol. 46, no. 1/2, pp. 1-12, 2013. 
[63] J. F. Hair, M. Sarstedt, C. M. Ringle, and J. A. Mena, "An assessment of the use of partial least squares structural equation modeling in marketing research," Journal of the Academy of Marketing Science, vol. 40, no. 3, pp. 414-433, 2012.

[64] K. K.-K. Wong, "Partial least squares structural equation modeling (PLS-SEM) techniques using Smart PLS," Marketing Bulletin, vol. 24, pp. 1-32, 2013.

[65] L. Surienty, T. Ramayah, M. c. Lo, and A. N. Tarmiz, "Quality of work-life and tunover intention: a partial least square (PLS) approach," Social Indicators Research, vol. 119, no. 1, pp. 405-420, 2013.

[66] B. W. Yap, T. Ramayah, and W. N. Shahidan, "Satisfaction and trust on customer loyalty: a PLS approach," Business Strategy Series, vol. 13, no. 4, pp. 154-167, 2012.

[67] J. Henseler, G. Hubona, and P. Ray, "Using PLS path modeling in new technology research: updated guidelines," Industrial Management \& Data Systems, vol. 116, pp. 2-20, 2016.

[68] J. Hulland, "Use of partial least squares (PLS) in strategic management research: a review of four recent studies," Strategic Management Journal, vol. 20, no. 2, pp. 195-204, 1999.

[69] S. M. Wu and D. Amtmann, "Psychometric evaluation of the perceived stress scale in multiple sclerosis," International Scholarly Research Notices, vol. 2013, Article ID 608356, 9 pages, 2013.

[70] C. Fornell and D. F. Larcker, "Evaluating structural equation models with unobservable variables and measurement error," Journal of Marketing Research, vol. 18, no. 3, pp. 382-388, 1981.

[71] J. F. Hair Jr., G. T. Hult, C. M. Ringle, and M. Sarstedt, $A$ Premier on Partial Least Squares Equation Modelling (PLSSEM), SAGE Publications Ltd., Thosand Oaks, CA, USA, 2nd edition, 2014.

[72] L. Jackson and S. Rothmann, "An adapted model of burnout for teachers in South Africa. Unpublished Ph. D. thesis," South African Journal of Education, vol. 25, no. 2, pp. 100-108, 2005.

[73] J. Henseler, C. M. Ringle, and M. Sarstedt, "A new criterion for assessing discriminant validity in variance-based structural equation modeling," Journal of the Academy of Marketing Science, vol. 43, no. 1, pp. 115-135, 2015.

[74] J. Henseler, C. M. Ringle, and R. R. Sinkovics, "The use of partial least squares path modeling in international marketing," in Advances in International Marketing (New Challenges to International Marketing, pp. 277-319, Emerald Group Publishing Limited JAI Press, Bingley, UK, 2009.

[75] E. E. Ringdon, "Rethinking partial least squares path modeling: breaking chains and forging ahead," Long Range Planning, vol. 47, no. 3, pp. 161-167, 2014.

[76] M. Sarstedt, C. M. Ringle, J. Henseler, and J. F. Hair, "On the emancipation of PLS-SEM," Long Range Planning, vol. 47, no. 3, 2014.

[77] J. F. Hair Jr., G. T. Hult, C. M. Ringle, and M. Sarstedt, $A$ Premier on Partial Least Squares Equation Modelling (PLSSEM), SAGE Publications Ltd, Thosand Oaks, CA, UK, 2017.

[78] M. Steinisch, R. Yusuf, J. Li et al., "Work stress: its components and its association with self-reported health outcomes in a garment factory in Bangladesh-findings from a crosssectional study," Health \& Place, vol. 24, pp. 123-130, 2013.

[79] A. Ahmad, A. Hussain, W. Qasar, and U. Badar, "Causes of workplace stress in textile industry of developing countries: a case study from Pakistan," in Advances in Social \& Occupational Ergonomics (Advances in Intelligent Systems and
Computing, R. Goossens, Ed., Springer, Cham, FL, USA, pp. 283-294, 2017.

[80] K. Turgeman-Lupo and M. Biron, "Make it to work (and back home) safely: the effect of psychological work stressors on employee behaviour while commuting by car," European Journal of Work and Organizational Psychology, vol. 26, no. 2, pp. 161-170, 2016.

[81] Y. Ge, W. Qu, C. Jiang, F. Du, X. Sun, and K. Zhang, "The effect of stress and personality on dangerous driving behavior among Chinese drivers," Accident Analysis \& Prevention, vol. 73, pp. 34-40, 2014.

[82] S. F. Gardazi, N. Mobeen, A. S. Gardazi, and S. A. Gardazi, "Causes of stress and burnout among working mothers in Pakistan," Qualitative Report, vol. 21, no. 5, pp. 916-932, 2016.

[83] A. U. Haque and J. Aston, "A relationship between occupational stress and organisational commitment of it sector'S employees in contrasting economies," Polish Journal of Management Studies, vol. 14, no. 1, pp. 95-105, 2016.

[84] S. Pindek and P. E. Spector, "Organizational constraints: a meta-analysis of a major stressor," Work \& Stress: An International Journal of Work, Health \& Organisations, vol. 30, no. 1, pp. 7-25, 2016.

[85] A. Ahmad, A. Hussain, M. P. Mughal, N. A. Mufti, and M. Q. Saleem, "Effects of workplace stress on managers of textile industries of developing countries: a case study from Pakistan," in Advances in Intelligent Systems and Computing (Advances in Human Factors, Business Management and Society, AHFE 2018, J. Kantola, S. Nazir, and T. Barath, Eds., Springer, Cham, Switzerland, pp. 500-507, 2019.

[86] A. Ikram, Q. Su, M. Fiaz, and R. U. Rehman, "Cluster strategy and supply chain management: the road to competitiveness for emerging economies," Benchmarking: An International Journal, vol. 25, no. 5, 2018. 